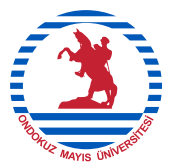

Samsun Sağlık Bilimleri Dergisi,

Journal of Samsun Health Sciences

e-ISSN: 2458-8857, JSHS August 2021, 6(2): 383-399

\title{
Pandemi Sürecinde Çalışan Hemşirelerin Sağlık Kaygısı ve Karşılanmayan Hemşirelik Bakım Gereksinimlerinin Belirlenmesi
}

\section{Health Anxiety of Nurses Working During Pandemic Process and Missed Nursing Care}

\author{
Afitap ÖZDELIKARA', Emine YAMAN²
}

\author{
1 Ondokuz Mayıs Üniversitesi, Sağlık Bilimleri Fakültesi, Iç Hastalıkları Hemşireliği Anabilim Dalı \\ - afitapozdelikara@gmail.com• ORCiD > 0000-0002-5896-9207 \\ 2 Ünye Devlet Hastanesi, Yoğun Bakım Servisi \\ •e_yaman95@hotmail.com• ORCID > 0000-0001-6600-0407
}

\author{
Makale Bilgisi / Article Information \\ Makale Türü / Article Types: Araştırma Makalesi / Research Article \\ Geliş Tarihi / Received: 16 Temmuz / July 2021 \\ Kabul Tarihi / Accepted: 7 Ağustos / August 2021 \\ Yıl/Year: 2021 | Cilt -Volume: 6 | Sayı - Issue: 2 | Sayfa / Pages: 383-399
}

Atıf/Cite as: Özdelikara, A. ve Yaman, E. “Pandemi Sürecinde Çalışan Hemşirelerin Sağlık Kaygısı ve Karşılanmayan Hemşirelik Bakım Gereksinimlerinin Belirlenmesi - Health Anxiety of Nurses Working During Pandemic Process and Missed Nursing Care". Samsun Sağlık Bilimleri Dergisi- Journal of Samsun Health Sciences 6(2), Ağustos 2021: 383-399. https://doi.org/10.47115/ ¡shs. 972178

Sorumlu Yazar: Afitap ÖZDELIKARA

Copyright @ Published by Ondokuz Mayıs Üniversitesi, Sağlık Bilimleri Fakültesi - Ondokuz Mayıs University, Faculty of Health Sciences, Samsun, Turkey. All rights reserved. 


\title{
PANDEMI SÜRECINDE ÇALIŞAN HEMŞIRELERIN SAĞLIK KAYGISI VE KARŞILANMAYAN HEMŞIRELIIK BAKIM GEREKSINIMLERININ BELIRLENMESI
}

\author{
ÖZ:
}

Amaç: Bu araştırma pandemi sürecinde çalışmakta olan hemşirelerin sağlık kaygısı ve karşılanmayan hemşirelik bakım gereksinimleri miktarı ve nedenlerini belirlemek amacıyla yapılmıștır.

Yöntem: Tanımlayıcı nitelikteki bu çalışmanın evreni pandemi döneminde aktif çalışan hemşireler oluşturmuştur. Araştırmanın örneklemini ise Şubat 2021 - Nisan 2021 tarihleri arasında, ülke genelinde ilgili birimlerde çalışan ve araştırmaya katılmayı kabul eden 200 hemşire oluşturmuştur. Verilerin toplanmasında, Tanıtıcı Form, Sağlık Kaygısı Derecelendirme Skalası ve Karşılanmayan Hemşirelik Bakım Gereksinimleri Ölçeği (KHBG) kullanılmıştır.

Bulgular: Hemşirelerin pandemi sürecinde kendi sağlıklarına ilişkin yaşadıkları sağlık kaygısı ortalaması 7,52 22,01 olarak belirlenmiştir. KHBG ölçeği karşılanmayan bakım gereksinimlerinin miktarı maddeleri incelendiğinde hemşirelerin \%23,5’i hastayı günde üç kez veya gerektiği kadar ayağa kaldırma/ dolaştırma, \%20 'si her iki saatte bir hastanın çevrilmesi ve \%19,5'i hastaya banyo yaptırılması/deri bakımının sıklıkla karşılanmadığını ifade etmiştir. KHBG ölçeği karşılanmayan hemşirelik bakım gereksinimlerinin nedenleri incelendiğinde, hemşirelerin \%84’ü çalışan personel sayısının yetersizliğini, \%80,5'i Hasta sayısında beklenmedik bir artış ya/ya da çalışılan birimde yoğunluğunu, 74,5’i Acil hasta durumunu önemli bir neden olarak bildirmiştir. KHBG alt boyutları ile sağlık kaygısı puanları arasında istatistiksel olarak anlamlı ilişki belirlenmemiştir ( $p>0,05)$.

Sonuç ve Öneriler: Hemşirelerin hasta ambulasyonuna yönelik olarak çalıştıkları klinik alana ilişkin eğitimlerinin desteklenmesi, iş yaşamına ilişkin süreçlerin hemşirelerin sağlık kaygısı üzerindeki etkisinin fark edilerek buna yönelik düzenlemelerin (personel sayısı, ekip çalışması vb.) yönetici iş birliği ile gerçekleştirilmesi, ve olası yeni vaka artışları için için hemşirelerin hem çalışma koşullarının iyileştirilmesi, hem de eğitim imkanlarının arttırılarak güçlendirilmesi gerekmektedir.

Anahtar Kelimeler: Hemşirelik; Covid 19; Sağlık kaygısl; Karşılanmayan hemşirelik bakımi; Pandemi

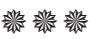

\section{HEALTH ANXIETY OF NURSES WORKING DURING PANDEMIC PROCESS AND MISSED NURSING CARE}




\section{ABSTRACT:}

Aim: This research was conducted to determine the amount and causes of health anxiety and missed nursing care needs of nurses working during the pandemic process.

Method: The population of this descriptive study consisted of active nurses during the pandemic period. The sample of the study consisted of 200 nurses working in the relevant units and agreed to participate in the study between February 2021 and April 2021. The Descriptive Form and the MISSCARE Survey were used to collect the data.

Results: The mean health anxiety experienced by nurses regarding their own health during the pandemic was determined as 7.52 \pm 2.01 . When the items on the amount of care needs not met in the MISSCARE scale are examined, 23.5\% of the nurses expect the patient to stand up/walk around three times a day or as needed, $20 \%$ to turn the patient every two hours, and $19.5 \%$ to give the patient a bath/skin care. stated that it is not often met. When the reasons for the nursing care needs that are not met in the MISSCARE scale are examined, $84 \%$ of the nurses identified the inadequacy of the number of staff, $80.5 \%$ of them as an unexpected increase in the number of patients and/or their density in the working unit, and 74.5 of them as an important reason for the emergency patient situation. reported. No statistically significant correlation was found between MISSCARE sub-dimensions and health anxiety scores $(\mathrm{p}>0.05)$.

Conclusions and Suggestions: Supporting the training of nurses in the clinical field in which they work for patient ambulation, realizing the effect of work-related processes on nurses' health anxiety and making arrangements (number of personnel, teamwork, etc.) for this with the cooperation of managers, and nurses for possible new pandemic waves. Both working conditions should be improved and training opportunities should be increased and strengthened.

Keywords: Nursing; Covid 19; Health anxiety; Missed nursing care; Pandemic

$$
\text { GíRiş }
$$

Tüm dünyayı etkisine alan COVİD 19 virüsü, küresel bir salgın yani "pandemi” olarak ilan edilmiştir (WHO, 2020). Hemşireler modern hemşireliğin başlangıcından bu yana, olağanüstü durumlarda, değerlendirme yapma, öncelikleri belirleme, iş birliğini sağlama ve bakımı yönetme rollerini üstlenmişlerdir (Kalanlar \& 
Kubilay, 2015). Bu duruma bağlı olarak sağlık çalışanları, özellikle hemşireler enfekte hastalara birebir bakım verdikleri için yüksek risk altında kalmaktadır (Chen ve ark., 2020). ICN'in (International Council of Nursing) açıklamaları bu riski doğrular niteliktedir. ICN, tüm sayılara ulaşılamamasına rağmen, dünya genelinde çok fazla sağlık çalışanının COVID-19 ile enfekte olduğu, 1500 hemşirenin ise bu infeksiyon nedeniyle yaşamını kaybettiği ancak dünya çapında sağlık çalışanı COVID-19 ölümlerinin 20.000'den fazla olabileceği ifade edilmiştir (ICN, 2020). Jiang ve arkadaşları (2020) pandemi sürecinde hastanın bakımıyla birebir ilgilenen hemşirelerin, virüse maruziyet riski taşımalarının yanı sıra ayrıca çalışma ortamı, uzun ve tempolu çalışma gibi sebeplerden dolayı fiziksel ve psiko-sosyal sorunlarla karşılaştığını, bunların yanı sıra uzun dönem ekipman kullanımının bir çok olumsuz etkisini yaşadıkları ve virüsü bir başkasına da taşıyabilecek olma endişesi ile büyük kaygılar yaşadıklarını ifade etmişler (Center for the Study of Traumatic, 2020; Jiang ve ark., 2020).

Öte yandan COVID-19 hastalığının yayılımının devam etmesi bu süreçte hastane kaynaklarına (koruyucu ekipman, sağlık tesisi, mekanik ventilatör, sağlık personeli) duyulan ihtiyacı daha fazla artmaktadır. Yeterli personel sayısı algısı, vardiyali/gündüz çalışma biçimi, hasta başına harcanan saat/gün sayısı gibi çalışma koşullarına ilişkin değişimler karşılanmayan hemşirelik bakım gereksinimlerinin oluşmasına zemin hazırlamaktadır (Zencir \& Eşer 2015; Kalisch ve ark. 2011). İhtiyaç duyulan hemşirelik bakımı günlük uygulamalarda bazen göz ardı edilebilmekte ve hasta güvenliğine yönelik tehditler oluşabilmektedir (Kalisch, 2009). Zorunlu olan hemşirelik bakımının tümünün ya da bir kısmının ihmal edilmesi ya da bakımın ertelenmesi karşılanmayan hemşirelik bakımı olarak ifade edilmektedir (Kalisch \& Xie, 2014). Karşılanmayan hemşirelik bakımı, hasta sonuçlarına olumsuz yansımakta, bakımın kalitesini ve hasta güvenliğini tehdit etmektedir (Hessels ve ark., 2015).

Pandemi döneminde hemşirelerin hem pandemiye yönelik hem çalışma koşullarına yönelik zor şartlarda görev aldığı ve bu durumun hastalara bakım sunarken verilen hemşirelik bakımının etkilenebileceği düşünülmektedir. Bu araştırma pandemi sürecinde çalışmakta olan hemşirelerin sağlık kaygısı ve karşılanmayan hemşirelik bakım gereksinimleri miktarı ve nedenlerini belirlemek amacıyla yapılmıştır.

\section{YÖNTEM}

\section{Araştırmanın tipi, evren ve örneklemi}

Tanımlayıcı nitelikteki bu çalışmanın evreni ülke genelinde ikinci ve üçüncü basamak sağlık kurumlarında aktif çalışan hemşireler oluşturmuştur. Araştırma- 
nın örneklemini ise Şubat 2021 - Nisan 2021 tarihleri arasında, ilgili birimlerde çalışan ve araştırmaya katılmayı kabul eden 200 hemşire oluşturmuştur. Örneklem seçiminde kartopu örneklem yöntemi uygulanmış, çalışmayı kabul eden ve araştırma konusu ile ilgili bağlantı kişileri seçilmiş ve bu kişiler aracılığı ile tüm örnekleme ulaşılmıştır. Ölçme araçları digital hale dönüştürülmüş ve elektronik ortamda katılımcılara ulaştırılmıştır.

\section{Veri toplama araçları ve uygulanması}

Verilerin toplanmasında, Tanıtıcı Form ve Karşılanmayan Hemşirelik Bakım Gereksinimleri Ölçeği kullanılmıştır.

Tanıtıcı form; Araştırmacılar tarafından hazırlanmıştır ve iki bölümden oluşmaktadır. İlk bölümde hemşirelere ait sosyo-demografik, mesleki özelliklere ait ikinci bölümde ise pandemi süreci ve sağlık kaygısına ilişkin toplamda 14 sorudan oluşmaktadır. Pandemi sürecinde kendi sağlıklarına ilişkin yaşadıkları sağlık kaygısını ise 1 ile 10 (1en düşük, 10 en yüksek sağlık kaygısı düzeyi) arasında skorlamaları istenmiştir.

Karşılanmayan hemşirelik bakım gereksinimleri ölçeği (KHBG); Kalisch ve Williams(2009) tarafından geliştirilen ölçeğin Türkçe geçerlilik ve güvenirliliğini Kalisch, Terzioğlu \& Duygulu (2012) gerçekleştirmiştir. Ölçekte, hem hemşirelerin karşılanmayan bakım gereksinimlerinin miktarını hem de nedenleri hakkındaki değerlendirmeleri içeren kısımlar bulunmaktadır. Ölçeğin ilk kısmında hemşirelerden karşılanmayan bakım gereksinimlerinin miktarı (KHBG-M- BÖLÜM A); (Nadiren verilmiyor, bazen verilmiyor, Sıklıkla verilmiyor, hiçbir zaman verilmiyor, uygun değil) beşli likert tipi ölçek kullanarak; ikinci kısmında ise karşılanmayan bakım gereksinimlerinin nedenlerini (KHBG-N- BÖLÜM B) (Önemli bir neden, orta düzeyde bir neden, küçük bir neden, bakımın verilmemesi için bir neden değil) dörtlü likert tipi ölçek kısmını kullanarak görüşlerini belirtmeleri istenmektedir. Ölçeğin değerlendirilmesinde, incelenen olayın miktarının veya sıklığının artıp azaldığını ifade eden, katılımcıların ulaşacağı herhangi bir puan aralığı bulunmamaktadır. Ölçeğin ilk kısmında puan artışı karşılanmayan hemşirelik bakım gereksiniminin miktarının arttığını gösterirken, ikinci bölümdeki puan artışı karşılanmayan hemşirelik bakım gereksiniminin nedenlerinin önem derecesini göstermektedir. Verilen cevaplara göre katılımcıların karşılanmayan hemşirelik bakımı konusunda algıladıkları sıklık miktarı ve nedenleri ortaya koyulmaktadır. Orijinal çalışmada ilk bölümünün Cronbach a değeri 0.93, ikinci bölümünün Cronbach adeğeri 0, 80 bulunmuştur. Bu çalışmada ölçeğin ilk bölümünün Cronbach $\alpha$ değeri 0.95; ölçeğin ikinci bölümünün Cronbach $\alpha$ değeri 0.91 olarak bulunmuştur. 


\section{Verilerin analizi}

$\mathrm{Bu}$ araştırmada elde edilen nicel veriler SPSS 25 programı kullanılarak analiz edilmiştir. Nicel veriler frekans, yüzde, ortalama-standart sapma, ortanca şeklinde sunulmuştur. Hemşirelerin tanıtıcı özelliklerine göre kaygı ve karşılanmayan bakım gereksinimi ilişkinin belirlenmesi amacıyla normal dağılım gösteren verilerin analizinde, gruplar arası karşılaştırmalarda üç veya daha fazla grup olması durumunda tek yönlü varyans analizi (ANOVA) kullanılmıştır. Normal dağılım göstermeyen verilerin analizinde gruplar arası karşılaştırmada Mann Whitney U testi, üç veya daha fazla grup olması durumunda Kruskal Wallis testi kullanılmıştır. İlişki değerlendirilmesinde spearman korelasyon analizi kullanılmıştır. Anlamlılık düzeyi p $<0,05$ olarak alınmıştır.

\section{Araştırmanın etik yönü}

Araştırmanın yapılabilmesi için, önce T.C. Sağlık Bakanlığı Covid 19 Bilimsel Araştırma Çalışmaları Biriminden izin (02-26T11_58_14.xml) daha sonra Ondokuz Mayıs Üniversitesi Sosyal ve Beşeri Bilimler araştırmaları Etik Kurulundan 2021/190 nolu etik onay alınmıştır. KHBG ölçeği için Türkçe uyarlama çalışmasını gerçekleştiren araştırmacılardan e-mail aracılığı ile izin alınmıştır. Katılımcılardan ise digital platformda onam alınmıştır.

\section{Araştırmanın Sinırlılıkları}

Araştırmada elde edilen ölçümler katılımcıların digital platformdaki öz bildirimleri ile sinırlıdır, genellenemez.

\section{BULGULAR}

Araştırmaya katılan hemşirelerin yaş ortalaması $29.55 \pm 6.73$ olarak belirlenmiştir. Hemşirelerin pandemi sürecinde kendi sağlıklarına ilişkin yaşadıkları sağlık kaygısı ortalaması ise $7.52 \pm 2.01$ olarak belirlenmiştir Katılımcıların \%91'inin kadın, \%54'ünün bekar, \%73.5'i lisans mezunu, \%44.5'inin Covid yoğun bakımda çalıştığı, \%84.5'inin vardiyalı çalıştı̆̆ 1 ve \% 57'sinin işinden memnun olduğu belirlenmiştir (Tablo1).

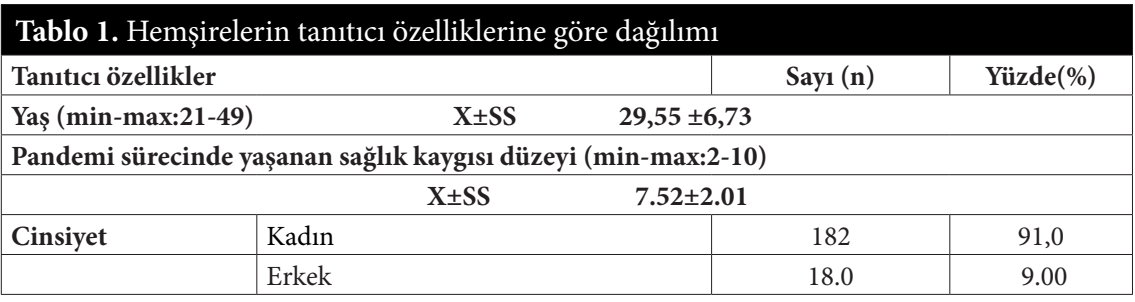




\begin{tabular}{|c|c|c|c|}
\hline \multicolumn{4}{|l|}{ Medeni Durum } \\
\hline & Evli & 92.0 & 46.0 \\
\hline & Bekar & 108 & 54.0 \\
\hline \multicolumn{4}{|l|}{ Eğitim Durumu } \\
\hline & Lise & 4.00 & 2.00 \\
\hline & Önlisans & 20.0 & 10.0 \\
\hline & Lisans & 147 & 73.5 \\
\hline & Lisansüstü & 29.0 & 14.5 \\
\hline \multicolumn{4}{|l|}{ Çalışılan Birim } \\
\hline & Covid Yoğun bakım servisi & 89.0 & 44.5 \\
\hline & Pandemi servisi & 40.0 & 20.0 \\
\hline & Pandemi dışı servisler & 71.0 & 35.5 \\
\hline \multicolumn{4}{|l|}{ Çalışma şekliniz } \\
\hline & Vardiyalı & 169 & 84.5 \\
\hline & Gündüz & 31.0 & 15.5 \\
\hline \multicolumn{4}{|c|}{ İşinden memnun olma durumu } \\
\hline & Evet & 114 & 57.0 \\
\hline & Hayır & 86.0 & 43.0 \\
\hline \multicolumn{4}{|c|}{ Hemşire sayısını yeterli bulma durumu } \\
\hline & Evet & 59.0 & 29.5 \\
\hline & Hayır & 141 & 70.5 \\
\hline \multicolumn{4}{|c|}{ Çalışma koşullarından memnun olma durumu } \\
\hline & Evet & 34.0 & 17.0 \\
\hline & Hayır & 166 & 83.0 \\
\hline \multicolumn{4}{|c|}{ Meslekten ayrılmayı düșünme durumu } \\
\hline & Evet & 104 & 52.0 \\
\hline & Hayır & 96 & 48.0 \\
\hline \multicolumn{4}{|c|}{ Covid 19 tanılı hastalara bakım verirken virüs bulaşma korkusu yașama durumu } \\
\hline & Evet & 176 & 88.0 \\
\hline & Hayır & 24 & 12.0 \\
\hline \multicolumn{4}{|c|}{ Covid 19 sürecinde gelecek hakkında kaygılı, endişeli hissetme durumu } \\
\hline & Evet & 185 & 92.5 \\
\hline & Hayır & 15 & 7.50 \\
\hline \multicolumn{4}{|c|}{ Covid 19 sürecinde hislerin ifade edilmesi } \\
\hline & Bunalmış & 138 & 69.0 \\
\hline & Mutsuz & 24 & 12.0 \\
\hline & Gergin & 35 & 17.5 \\
\hline & Her zamanki gibi & 3 & 1.5 \\
\hline \multicolumn{4}{|c|}{ Covid 19 tanısı alan hastalara yeterli bakımı verme durumu } \\
\hline & Evet & 129 & 64.5 \\
\hline & Hayır & 71 & 35.5 \\
\hline
\end{tabular}


Hemşirelerin. \%70.5'i çalıştığı birimde hemşire sayısını yeterli bulmadığını, \%83'ü çalışma koşullarından memnun olmadığını, \%52'si meslekten ayrılmayı düşündügünü, \%88'i Covid 19 tanılı hastalara bakım verirken virüs bulaşma korkusu yaşadığını, \%92.5'i Covid 19 sürecinde gelecek hakkında kaygılı, endişeli hissettiğini, \% 69'u bunalmış hissettiğini ve \% 64.5'i Covid 19 tanısı alan hastalara yeterli bakımı verdiğini ifade etmiştir (Tablo 1 ).

KHBG ölçeği karşılanmayan bakım gereksinimlerinin miktarı maddeleri incelendiğinde hemşirelerin \%23.5'i hastayı günde üç kez veya gerektiği kadar ayağa kaldırma/ dolaştırma. \%20'si her iki saatte bir hastanın çevrilmesi ve \%19.5’i hastaya banyo yaptırılması/deri bakımının sıklıkla karşılanmadığını ifade etmiştir (Tablo 2).

\begin{tabular}{|c|c|c|c|c|c|}
\hline $\begin{array}{l}\text { KHBG-M (BÖLÜM A) } \\
\text { Maddeleri }\end{array}$ & $\begin{array}{l}\text { Nadiren } \\
\text { Verilmiyor }\end{array}$ & $\begin{array}{c}\text { Bazen } \\
\text { Verilmiyor }\end{array}$ & $\begin{array}{l}\text { Siklıkla } \\
\text { Verilmiyor }\end{array}$ & $\begin{array}{c}\text { Hiçbir zaman } \\
\text { Verilmiyor }\end{array}$ & $\begin{array}{l}\text { Uygun } \\
\text { değil }\end{array}$ \\
\hline \multicolumn{2}{|r|}{ n(\%) } & \multicolumn{2}{|l|}{$\mathbf{n}(\%)$} & $\mathrm{n}(\%)$ & $\mathbf{n}(\%)$ \\
\hline $\begin{array}{l}\text { Hastayı günde üç kez } \\
\text { veya gerektiği kadar aya- } \\
\text { ga kaldırma/ dolaştırma }\end{array}$ & $48(24.0)$ & $44(22.0)$ & $47(23.5)$ & $22(11.0)$ & $39(19.5)$ \\
\hline $\begin{array}{l}\text { Her iki saatte bir hasta- } \\
\text { nın çevrilmesi }\end{array}$ & $81(40.5)$ & $52(26.0)$ & $40(20.0)$ & $5(2.5)$ & $22(11)$ \\
\hline $\begin{array}{l}\text { Hastanın yemek henüz } \\
\text { sicakken beslenmesi }\end{array}$ & $99(49.5)$ & $54(27.0)$ & $17(8.5)$ & $8(4.0)$ & $22(11.0)$ \\
\hline $\begin{array}{l}\text { Kendileri beslenebilen } \\
\text { hastaların yemeklerinin } \\
\text { hazır edilmesi }\end{array}$ & $141(70.5)$ & $28(14.0)$ & $9(4.5)$ & $5(2.5)$ & $17(8.5)$ \\
\hline $\begin{array}{l}\text { Illaçların belirlenen saat- } \\
\text { ten } 30 \text { dakika önce veya } \\
\text { sonraki süre içerisinde } \\
\text { hastaya verilmesi }\end{array}$ & $146(73.0)$ & $28(14.0)$ & $7(3.5)$ & $3(1.5)$ & $16(8.0)$ \\
\hline $\begin{array}{l}\text { Hastanın hayati bulgu- } \\
\text { larının istem edildiği şe- } \\
\text { kilde değerlendirilmesi }\end{array}$ & $161(80.5)$ & $24(12.0)$ & $1(0.50)$ & $2(1.00)$ & $12(6.0)$ \\
\hline $\begin{array}{l}\text { Hastanın aldığı çıkardı- } \\
\text { ğının takip edilmesi }\end{array}$ & $152(76.0)$ & $15(7.50)$ & $11(5.50)$ & $2(1.00)$ & $20(10.0)$ \\
\hline $\begin{array}{l}\text { Gerekli tüm verilerin } \\
\text { tam olarak kaydedilmesi }\end{array}$ & $151(71.5)$ & $13(6.50)$ & $20(10.0)$ & $5(2.50)$ & $11(5.50)$ \\
\hline $\begin{array}{l}\text { Hastaya hastane kuralla- } \\
\text { rı, testler ve diğer tanısal } \\
\text { islemler hakkında eğitim } \\
\text { verilmesi }\end{array}$ & $106(53.0)$ & $37(18.5)$ & $32(16.0)$ & $12(6.00)$ & $13(6.50)$ \\
\hline $\begin{array}{l}\text { Hastaya ve/veya hasta } \\
\text { yakınlarina duygusal } \\
\text { destek verilmesi }\end{array}$ & $78(39.0)$ & $48(24.0)$ & $35(17.5)$ & $26(13.0)$ & $13(6.50)$ \\
\hline $\begin{array}{l}\text { Hastaya banyo yaptıril- } \\
\text { masi/deri bakımı veril- } \\
\text { mesi }\end{array}$ & $68(34.0)$ & $50(25.0)$ & $39(19.5)$ & $17(8.50)$ & $26(13.0)$ \\
\hline
\end{tabular}




\begin{tabular}{|c|c|c|c|c|c|}
\hline $\begin{array}{l}\text { Hastaya ağız bakımı ve- } \\
\text { rilmesi }\end{array}$ & $98(49.0)$ & $47(23.5)$ & $23(11.5)$ & $11(5.50)$ & $21(10.5)$ \\
\hline $\begin{array}{l}\text { Taburcu olan hastanın } \\
\text { kullanacağ1 } \\
\text { dozu, alıçların } \\
\text { yan etkilerinin hasta ile } \\
\text { birlikte gözden geçiril- } \\
\text { mesi }\end{array}$ & $107(53.5)$ & $37(18.5)$ & $17(8.50)$ & $17(8.50)$ & $22(11.0)$ \\
\hline $\begin{array}{l}\text { Hastalık süreci hakkında } \\
\text { eğitim verilmesi }\end{array}$ & $108(54.0)$ & $25(12.5)$ & $30(15.0)$ & $18(9.00)$ & $19(9.50)$ \\
\hline Ellerin yıkanması & $157(78.5)$ & $14(7.00)$ & $10(5.00)$ & $3(1.50)$ & $16(8.00)$ \\
\hline $\begin{array}{l}\text { Taburculuk } \\
\text { kontrole gelme zamanı } \\
\text { ve taburculuk sonrası } \\
\text { bakımlarına yönelik ya- } \\
\text { pılan planlar hakkında } \\
\text { hastaya eğitim verme }\end{array}$ & $113(56.5)$ & $27(13.5)$ & $11(5.50)$ & $19(9.50)$ & $30(15.0)$ \\
\hline $\begin{array}{l}\text { İsteme göre yatak ba- } \\
\text { şında kan şekeri takibi } \\
\text { yapılması }\end{array}$ & $169(84.5)$ & $9(4.50)$ & $4(2.00)$ & $3(1.50)$ & $15(7.50)$ \\
\hline $\begin{array}{l}\text { Her şiftte hastanın de- } \\
\text { ğerlendirilmesi }\end{array}$ & $163(81.5)$ & $13(6.50)$ & $8(4.00)$ & $1(0.50)$ & $15(7.50)$ \\
\hline $\begin{array}{l}\text { Hastane politikasına } \\
\text { göre intravenöz giriş } \\
\text { yerinin bakımı ve değer- } \\
\text { lendirmesi }\end{array}$ & $150(75.0)$ & $29(14.50)$ & $8(4.00)$ & $1(0.50)$ & $15(7.50)$ \\
\hline $\begin{array}{l}\text { Çağrı sinyaline/ziline } 5 \\
\text { dakika içinde yanıt ve- } \\
\text { rilmesi }\end{array}$ & $134(67.5)$ & $28(14.0)$ & $13(6.50)$ & $3(1.50)$ & $22(11.0)$ \\
\hline $\begin{array}{l}\text { Acil ilaç istemlerinin } 15 \\
\text { dakika içinde karşılan- } \\
\text { ması }\end{array}$ & $143(71.50)$ & $28(14.0)$ & $13(6.50)$ & $3(1.50)$ & $22(11.0)$ \\
\hline $\begin{array}{l}\text { Verilen ilaçların etkilili- } \\
\text { ğinin değerlendirilmesi }\end{array}$ & $148(74.00)$ & $30(15.0)$ & $8(4.00)$ & $4(2.00)$ & $10(5.00)$ \\
\hline $\begin{array}{l}\text { Doktorlarla vizite katıl- } \\
\text { ması }\end{array}$ & $141(70.5)$ & $29(14.5)$ & $7(3.50)$ & $5(2.50)$ & $18(9.00)$ \\
\hline $\begin{array}{l}\text { Düzenlenen disiplinlera- } \\
\text { rası bakım konferansla- } \\
\text { rına katılınması }\end{array}$ & $85(42.50)$ & $33(16.5)$ & $35(17.5)$ & $26(13.0)$ & $21(10.5)$ \\
\hline $\begin{array}{l}\text { Hastanın tuvalet gereksi- } \\
\text { nimlerine } 5 \text { dakika için- } \\
\text { de yardım edilmesi }\end{array}$ & $89(44.50)$ & $52(26.0)$ & $25(12.5)$ & $15(7.50)$ & $19(9.50)$ \\
\hline $\begin{array}{l}\text { Yara bakımı ya da teda- } \\
\text { visi }\end{array}$ & $142(71.0)$ & $20(10.0)$ & $17(8.50)$ & $4(2.00)$ & $17(8.50)$ \\
\hline
\end{tabular}

KHBG ölçeği karşılanmayan hemşirelik bakım gereksinimlerinin nedenleri incelendiğinde, hemşirelerin \%84'ü çalışan personel sayısının yetersizliğini, \%80.5’i Hasta sayısında beklenmedik bir artış ya/ya da çalışılan birimde yoğunluğunu, \%74.5'i Acil hasta durumunu önemli bir neden olarak bildirmiştir (Tablo 3). 
Tablo 3. KHBG-N (BÖLÜM B) alt boyut maddeleri puan ortalamaları

\begin{tabular}{|c|c|c|c|c|}
\hline $\begin{array}{l}\text { KHBG-N (BÖLÜM B) } \\
\text { Maddeleri }\end{array}$ & \begin{tabular}{|c|} 
Bakımın \\
verilmemesi \\
$\begin{array}{c}\text { için bir neden } \\
\text { değil }\end{array}$ \\
\end{tabular} & $\begin{array}{l}\text { Küçük bir } \\
\text { neden }\end{array}$ & Orta bir neden & $\begin{array}{c}\text { Önemli bir } \\
\text { neden }\end{array}$ \\
\hline & $\mathbf{n}(\%)$ & $\mathbf{n}(\%)$ & $\mathbf{n}(\%)$ & $\mathbf{n}(\%)$ \\
\hline $\begin{array}{l}\text { Çalışan personel sayısının } \\
\text { yetersizliği }\end{array}$ & $5(2.50)$ & $10(5.00)$ & $17(8.50)$ & $168(84.0)$ \\
\hline $\begin{array}{l}\text { Hasta sayısında beklenme- } \\
\text { dik bir artış ya/ya da çalış1- } \\
\text { lan birimde yoğunluk }\end{array}$ & $8(4.00)$ & $9(4.50)$ & $22(11.0)$ & $161(80.5)$ \\
\hline $\begin{array}{l}\text { Acil hasta durumu (örn. Bir } \\
\text { hastanın durumundaki ani } \\
\text { değişiklikler) }\end{array}$ & $4(2.00)$ & $14(7.00)$ & $33(16.5)$ & $149(74.5)$ \\
\hline $\begin{array}{l}\text { Yardımcı ve teknik personel } \\
\text { sayısının yetersizliği }\end{array}$ & $3(1.50)$ & $17(8.50)$ & $39(19.5)$ & $141(70.5)$ \\
\hline $\begin{array}{l}\text { Gerektiğinde malzeme/ci- } \\
\text { hazların uygun bir biçimde } \\
\text { çalışmaması }\end{array}$ & $6(3.00)$ & $17(8.50)$ & $37(18.5)$ & $140(70.0)$ \\
\hline $\begin{array}{l}\text { Gerektiğinde malzeme/ci- } \\
\text { hazların mevcut olmaması }\end{array}$ & $6(3.00)$ & $17(8.50)$ & $39(19.5)$ & $138(69.0)$ \\
\hline $\begin{array}{l}\text { Serviste deneyimsiz perso- } \\
\text { nel sayısının fazla olması }\end{array}$ & $6(3.00)$ & $23(11.5)$ & $43(21.5)$ & $128(64.0)$ \\
\hline $\begin{array}{l}\text { Hasta dağılımındaki denge- } \\
\text { sizlik }\end{array}$ & $3(1.50)$ & $32(16.0)$ & $38(19.0)$ & $127(63.5)$ \\
\hline $\begin{array}{l}\text { Hasta kabulü ve taburculuk } \\
\text { aktivitelerinin yoğun olması }\end{array}$ & $3(1.50)$ & $23(11.5)$ & $49(24.5)$ & $125(62.5)$ \\
\hline $\begin{array}{l}\text { Doktorlarla/Tibbı personel- } \\
\text { le oluşan gerilim veya ileti- } \\
\text { şim kopukluğu }\end{array}$ & $9(4.50)$ & $20(10.0)$ & $51(25.5)$ & $120(60.0)$ \\
\hline $\begin{array}{l}\text { Diğer yardımc1/destek bö- } \\
\text { lümleriyle iletisim kopuklu- } \\
\text { ğu veya gerginlik }\end{array}$ & $7(3.50)$ & $22(11.0)$ & $56(28.0)$ & $115(57.5)$ \\
\hline $\begin{array}{l}\text { Önceki şiftten veya gönde- } \\
\text { rilen servisten yetersiz hasta } \\
\text { teslimi }\end{array}$ & $12(6.00)$ & $29(14.5)$ & $45(22.5)$ & $114(57.0)$ \\
\hline $\begin{array}{l}\text { Ekip üyelerinden desteğin } \\
\text { yetersiz olması }\end{array}$ & $11(5.50)$ & $19(9.50)$ & $57(28.50)$ & $113(56.5)$ \\
\hline $\begin{array}{l}\text { Gerekli olduğunda ilaçların } \\
\text { bulunmaması }\end{array}$ & $15(7.50)$ & $38(19.0)$ & $38(19.0)$ & $109(54.5)$ \\
\hline $\begin{array}{l}\text { Hemşirenin hemşirelik ba- } \\
\text { kım hizmeti dişındaki her- } \\
\text { hangi bir nedenle servisten } \\
\text { ayrilması veya kendisine } \\
\text { ulaşllamaması }\end{array}$ & $19(9.50)$ & $32(16.0)$ & $40(20.0)$ & $109(54.5)$ \\
\hline $\begin{array}{l}\text { Diğer sağlık meslek grupla- } \\
\text { rının gereken bakımı/hiz- } \\
\text { meti sağlamaması }\end{array}$ & $12(6.00)$ & $28(14.0)$ & $54(27.0)$ & $106(53.0)$ \\
\hline $\begin{array}{l}\text { Hemşireler arasında oluşan } \\
\text { gerginlik veya iletişim ko- } \\
\text { pukluğu }\end{array}$ & $11(5.50)$ & $28(14.0)$ & $58(29.0)$ & $103(51.5)$ \\
\hline
\end{tabular}


Tablo 4. Hemşirelerin pandemi sürecine ilişkin bilgilerinin KHBG alt boyut ve Sağlık Kaygısı puanlarına göre dağılımı

\begin{tabular}{|c|c|c|c|c|}
\hline Değişkenler & & $\begin{array}{c}\text { KHBG-M } \\
\text { (BÖLÜM A) }\end{array}$ & $\begin{array}{l}\text { KHBG-N } \\
\text { (BÖLÜM B) }\end{array}$ & $\begin{array}{c}\text { Sağlık Kaygısı } \\
\text { Ortalaması }\end{array}$ \\
\hline \multicolumn{5}{|c|}{ Hemşire sayısı yeterli bulma durumu } \\
\hline & Evet & $1.46(1-5.00)$ & $1.58(1-3.24)$ & $7.0(2-10)$ \\
\hline & Hayır & $1.65(1-1.81)$ & $1.41(1-3.00)$ & $8.0(2-10)$ \\
\hline \multicolumn{5}{|c|}{$U=3569.5 p=0.114 \quad U=3285.5 p=0.019 \quad U=2803 \quad p<0.001$} \\
\hline \multicolumn{5}{|c|}{ Çalışma koşullarından memnun olma durumu } \\
\hline & Evet & $1.38(1-5.00)$ & $1.41(1-3.24)$ & $6.5(2-10)$ \\
\hline & Hayır & $1.59(1-4.81)$ & $1.44(1-3.00)$ & $8.0(2-10)$ \\
\hline \multicolumn{3}{|c|}{$\mathrm{U}=2457 \mathrm{p}=0.234$} & $\mathrm{U}=2464 \mathrm{p}=0.243$ & $U=2035.5 p<0.05$ \\
\hline \multicolumn{5}{|c|}{ Meslekten ayrılmayı düşünme durumu } \\
\hline & Evet & $1.50(1-5.00)$ & $1.41(1-3.24)$ & $8.0(2-10)$ \\
\hline & Hayır & $1.65(1-5.00)$ & $1.52(1-3.00)$ & $7.0(2-10)$ \\
\hline \multicolumn{5}{|c|}{$\mathrm{U}=4449.5 \quad \mathrm{p}=0.184 \quad \mathrm{U}=4408.5 \mathrm{p}=0.152 \quad \mathrm{U}=\mathbf{3 7 9 3 . 5} \mathbf{p}<\mathbf{0 . 0 5}$} \\
\hline \multicolumn{5}{|c|}{ Çalıșılan Birim } \\
\hline & $\begin{array}{l}\text { Yoğun bakım } \\
\text { servisi }\end{array}$ & $1.65(1-5.00)$ & $1.35(1-3.24)$ & $7(2-10)$ \\
\hline & Pandemi servisi & $1.50(1.08-5)$ & $1.47(1-3.00)$ & $9(4-10)$ \\
\hline & $\begin{array}{l}\text { Pandemi dış1 } \\
\text { servisler }\end{array}$ & $1.57(1-5.00)$ & $1.58(1-3.00)$ & $8(3-10)$ \\
\hline \multirow{2}{*}{\multicolumn{5}{|c|}{$\begin{array}{l}\qquad \mathrm{X}^{2}=0.257 \quad \mathrm{p}=0.879 \quad \mathrm{X}^{2}=4.542 \quad \mathrm{p}=0.103 \quad \mathrm{X}^{2}=\mathbf{8 . 6 8 0} \quad \mathrm{p}<\mathbf{0 . 0 5} \\
\text { Covid } 19 \text { tanılı hastalara bakım verirken virüs bulasma korkusu vasama durumu }\end{array}$}} \\
\hline & & & & \\
\hline & Evet & $1.53(1-5.00)$ & $1.41(1-3.24)$ & $8.0(3-10)$ \\
\hline & Hayır & $2.00(1.04-5)$ & $1.64(1-3.00)$ & $4.5(2-8)$ \\
\hline \multicolumn{5}{|c|}{$\mathrm{U}=1755.0 \mathrm{p}=0.179 \mathrm{U}=1755.5 \mathrm{p}=0.179 \mathrm{U}=493.5 \mathbf{p}<\mathbf{0 . 0 0 1}$} \\
\hline \multicolumn{5}{|c|}{ Covid 19 tanısı alan hastalara yeterli bakımı verme durumu } \\
\hline & Evet & $1.50(1-5.00)$ & $1.41(1-3.24)$ & $8.0(2-10)$ \\
\hline & Hayır & $1.84(1.04-5)$ & $1.47(1-2.53)$ & $8.0(3-10)$ \\
\hline \multicolumn{3}{|c|}{$\mathrm{U}=3860.5 \mathrm{p}=0.066$} & $=4282.5 \mathrm{p}=0.047$ & $\mathrm{U}=4193.0 \mathrm{p}=0.316$ \\
\hline
\end{tabular}

p:anlamlılık değeri, $\mathrm{X}^{2}$ : Kruskal - Wallis test istatistiği, $\mathrm{U}:$ Mann -Withney $\mathrm{U}$ test istatistiği

Hemşirelerin pandemi sürecine ilişkin bilgilerinin KHBG alt boyut ve Sağlık Kaygısı puanlarına göre dağılımı incelendiğinde; KHBG alt boyutlarından KHBG-N’nin hemşire sayısını yeterli bulma değişkeninden etkilendiği ve hemşire sayısını yeterli bulmayanların ortalamalarının daha düşük olduğu belirlenmiştir $(\mathrm{p}<0,001)$. Sağlık kaygısı ortalama puanlarının ise, işinden memnun olmayan, pandemi servisinde çalışan, hemşire sayısını yeterli bulmayan, çalışma koşullarından memnun olmayan, meslekten ayrılmayı düşünen, Covid 19 tanılı hastalara bakım verirken virüs bulaşma korkusu yaşayan ve Covid 19 sürecinde gelecek hakkında kaygılı, endişeli hisseden hemşirelerde daha yüksek olduğu belirlenmiştir $(\mathrm{p}<0,05$, Tablo 4). 
Tablo 5'de KHBG alt boyutları ile sağlık kaygısı puanları arasındaki ilişki verilmiştir. Buna göre KHBG alt boyutları ile sağlık kaygısı puanları arasında istatistiksel olarak anlamlı ilişki belirlenmemiştir ( $\mathrm{p}>0,05)$.

\section{Tablo 5. KHBG alt boyutları ile sağlık kaygısı puanları arasındaki ilişki*}

\begin{tabular}{|lc|}
\hline KHBG & Sağlık Kaygisı Ortalamas \\
\hline KHBG-M (BÖLÜM A) & $r=0,00$ \\
& $\mathrm{p}=0,945$ \\
\hline KHBG-N (BÖLÜM B) & $\mathrm{r}=-0,04$ \\
& $\mathrm{p}=0,517$ \\
\hline
\end{tabular}

${ }^{\star}$ Spearman korelasyon analizi

\section{TARTIŞMA}

Araştırmaya katılan hemşirelerin karşılanmayan hasta bakım gereksinimleri miktarına (Bölüm A) bakıldığında hastayı günde üç kez veya gerektiği kadar ayağa kaldırma/ dolaştırma (\%23.5), her iki saatte bir hastanın çevrilmesi (\%20) ve hastaya banyo yaptırılması/deri bakımının (\%19.5) sıklıkla karşılanmadığı belirlenmiştir (Tablo 2). Vogelsang ve arkadaşları (2021) covid pandemisi sürecinde yaptığı araştırmasında düzenlenen disiplinler arası konferanslara katılım (\%54.3), her 2 saatte bir hastayı çevirmek (\%54) ve günde üç kez ya da gerektiğinde ambulasyonun (\%45.2) en sık karşılanmayan hemşirelik bakım gereksinimi olarak bildirilmiştir. Cho ve arkadaşları (2018) bu araştırma sonuçlarına benzer şekilde her iki saatte bir hastayı döndürme $(\% 83.9)$, hasta banyosu/deri bakımı $(\% 81,5)$ ve ambulasyonun (\%78.7) en sık karşılanmayan hemşirelik bakım gereksinimleri olduğunu bildirmiştir. Literatürde karşılanmayan hemşirelik bakım gereksinimleri miktarına ilişkin oranlar farklılık gösterse de hastanın ambulasyonu ve yatak içi çevrilmesi genellikle en sık karşılanmayan gereksinim olarak görülmektedir. (Palase ve ark., 2015; İlaslan \& Yıldırım, 2019; Eskici, 2020). Kalish ve arkadaşları (2011) 4086 hemşire ile yürüttüğü çalışmasında hasta mobilizasyonunun en sık karşılanmayan (\%30.5) hemşirelik bakım gereksinimi olduğunu bildirmiştir. Vogelsang ve arkadaşları (2021) çalışmasında karşılanmayan hemşirelik gereksinimlerinde Covid 19 pandemisi öncesi döneme göre değişiklik olmadığını bildirmiştir. Hasta ambulasyonu ve yatak içi pozisyonlama hemşirenin hastanın durumuna göre değerlendirerek yapması gereken bakımlardan biridir. Mobilizasyon ve pozisyon verme özel alan hemşirelerinin (Yoğun bakım hemşiresi, acil hemşiresi vb.) görev ve sorumlulukları arasında yer almakta ve pozisyon verme Hemşirelik Yönetmeliği’ne (Resmi gazete 19/4/2011) göre hareketsizlik yönetimine ilişkin tanımlanmış hekimle işbirliği içinde yapılacak girişimlerden biridir. Literatürde ki bu sonuçlar pandemiden bağımsız olarak hastalara ilişkin bu gereksinimin karşılanmadığını düşündürmüştür. 
Karşılanmayan hemşirelik bakım gereksinimlerinin nedenlerine (Bölüm B) bakıldığında ise hemşireler pandemi döneminde, çalışan personel sayısının yetersizliği (\%84), hasta sayısında beklenmedik bir artış ya/ya da çalışılan birimde yoğunluk (\%80.5), acil hasta durumunu (\%74.5) en önemli ilk üç neden olarak bildirmiştir (Tablo 3). Vogelsang ve arkadaşları (2021) ise bu araştırma sonuçlarına benzer şekilde ünitede hasta hacminde ve/veya yoğunluğunda beklenmeyen artış (\%79.8), acil hasta durumları (\%72.9), yetersiz personel sayısını (\%68.9) karşllanmayan hemşirelik gereksinimlerin en önemli nedenleri olarak bildirilmiştir. Literatüre bakıldığında çalışılan personel yetersizliği, çalışılan birimde oluşan yoğunluk, acil hasta ya da hasta kabulü ve taburculuk işlemlerindeki artış en önemli nedenler arasındadır (Henderson 2020; Palase ve ark; 2015; İlaslan ve Yıldırım 2019 Eskici, 2020). Covid 19 sürecinde de benzer nedenler öne çıkmıştır. Sager ve arkadaşları (2018) karşılanmayan hemşirelik bakımı gereksiniminin en yaygın nedeninin iş gücü kaynakları ile ilgili olduğunu bildirmiştir. Ekonomik Kalkınma ve İşbirliği Örgütü (OECD) (2019) verilerine göre; Türkiye’de 1000 kişi başına düşen hemşire sayısı 2.4 olarak bildirilmiştir. Bu sayı Amerika birleşik devletleri için 12, İngiltere için 8.2 olarak belirlenmiştir. OECD ülkelerine bakıldığında Türkiye en düşük hemşire sayısına sahip ikinci ülke konumundadır (OECD, 2021).

Hemşirelerin pandemi sürecine ilişkin KHBG alt boyutlarına göre dağılımına bakıldığında; sadece karşılanmayan hemşirelik bakım gereksinimi nedenlerinin (Bölüm B) hemşire sayısını yeterli bulma durumundan etkilendiği belirlenmiştir ( $\mathrm{p}<0.05$, Tablo 4). White ve arkadaşları (2019) hemşirelerin \%72'sinin zaman ya da kaynak yetersizliği nedeniyle son vardiyalarında bir veya daha fazla bakım görevlerini karşılayamadıklarını bildirilmiştir. Ayrıca Griffiths ve arkadaşları (2014), 11 ve üzerinde hastaya bakım veren hemşirelerin altı ve daha az sayıda hastaya bakan hemşirelere göre bakımları \%26 oranla daha fazla karşılayamadığını belirlemiştir. Araştırma sonucu literatür ile benzerlik göstermektedir.

Araştırmada istatistiksel anlamlılık bulunmamasına karşın hemşire sayısını yeterli bulmayan, çalışma koşullarından memnun olmayan ve meslekten ayrılmayı düşünen ve yoğun bakımda çalışan hemşirelerin karşılanmayan hemşirelik bakım gereksinimleri miktarı ortalamalarının yüksek olması dikkat çekicidir ( $p>0,05$, Tablo 4). Alsubhi ve arkadaşları (2020) yaptıkları sistematik derlemede iş memnuniyetsizliği, mesleği bırakma düşüncesinin ihtiyaç duyulan bakımın karşılanması önünde bir engel olduğunu ve bunun hastalara sunulan bakımın kalitesi için önemli bir risk taşıdığını bildirmişlerdir. Duffy ve arkadaşları (2018) işten ayrılma niyeti, mevcut koşullarından ve ekip çalışmasından memnun olmama gibi durumların karşılanmayan hemşirelik bakım gereksinimi puanlarını arttırdığını bildirmiştir. Aynı çalışmada cerrahi klinikler, yoğun bakım ve anne-bebek ünitelerinde diğer kliniklerden çok daha fazla karşılanmayan hemşirelik bakım gereksinimleri olduğunu saptanmıştır. Araştırmanın sonuçları literatür ile benzerlik göstermektedir. 
Hemşirelerin sağlık kaygısı düzeylerine bakıldığında; hemşire sayısını yeterli bulmayan, çalışma koşullarından memnun olmayan ve meslekten ayrılmayı düşünen hemşirelerin sağlık kaygısının daha yüksek olduğu belirlenmiştir $(p<0,05)$. Sampaio ve ark (2020) pandemi sürecinde yeterli koruyucu ekipmana ulaşamama ve fazla mesai gibi iş yerine ilişkin unsurların hemşirelerin mental sağlığını olumsuz etkilediğini bildirmiştir.

Sağlık kaygısının çalışılan birim değişkeninden etkilendiği ve pandemi servisinde çalışan hemşirelerin sağlık kaygısının daha yüksek olduğu belirlenmiştir $(\mathrm{p}<0,05)$. Covid 19 tanılı hastalara bakım verirken virüs bulaşma korkusu yaşayan ve Covid 19 sürecinde gelecek hakkında kaygıll, endişeli hisseden hemşirelerin sağlık kaygısının yüksek olduğu belirlenmiştir $(\mathrm{p}<0,05)$. Salgının ne kadar devam edeceği ve sonucu ile ilgili belirsizlik kaygıyı artırmaktadır (Çiçek \& Almalı, 2020). Ayrıca hemşirelerin sürekli hasta grupla iletişim içinde olması kendi sağlıkları ile ilgili endişe ve kaygılarını arttırmaktadır (Şimşekoğlu \& Mayda, 2016). Arpacıŏ̆lu ve arkadaşları (2021) Covid hastaları ile doğrudan çalışan sağlık personelinin COVID 19 korkusunu anlamlı derecede daha yüksek olduğunu bildirmiştir. Salari ve arkadaşları yaptıkları meta analiz çalışmasında ön saflarda çalışan hemşirelerin depresyon prevalansının \%28, anksiyete prevalansını ise \%22.8 olarak bildirmişlerdir. Lai ve arkadaşları (2021) çalışmasında pandeminin çıkış noktası olan Wuhan'da çalışan sağlık personelinin anksiyete, depresif belirtiler, uykusuzluk ve stres gibi durumları çok daha yaşadığını bildirmiştir. İlgili literatür incelendiğinde Covid ile temas olasılığını arttırabilecek süreçlerin sağlık kaygısını ve buna ilişkin semptomların görülme sıklığını arttırdığı düşünülmüştür.

Karşılanmayan hemşirelik bakım gereksinimleri ile sağlık kaygısı arasında anlamlı korelasyon belirlenmemiştir ( $p>0,05$, Tablo 5). Vogelsang ve arkadaşları (2021) pandemi sürecinin zorluklarına rağmen hemşirelerin bakım kalitesinin pandemi öncesi dönem ile benzer olduğunu, bakım kalitesi ve hasta güvenliğinin korunduğunu bildirmiştir. Araştırma sonucu bu çalışma ile benzerlik göstermektedir. Bu sonuç hemşirelerin olası riskler sonucu ortaya çıkan sağlık kaygısını hemşirelik bakımına olumsuz bir biçimde yansıtmasına izin vermediklerini düşündürmüştür. Hemşirelerin bundan öncesinde olduğu gibi pandemi sürecinde de hemşirelik meslek andında ifade edildiği şekilde “.......hayatı korumak, 1stırabı hafifletmek, sağlığı yüceltmek için gerekecek her türlü çabay1.....” gösterdiği düşünülmektedir.

\section{SONUÇ VE ÖNERILER}

$\mathrm{Bu}$ araştırma sonucunda hemşirelerin sağlık kaygısının yüksek olduğu (7.52 \pm 2.01$)$, hasta ambulasyonunun (\%23.5) en sık karşılanmayan hemşirelik bakım gereksinimi olduğu, karşılanmayan hemşirelik bakım gereksinimlerinin 
nedenlerine bakıldığında ise çalışan personel sayısının yetersizliğinin (\%84) en önemli neden olarak ortaya çıktığ kım gereksinimleri ile sağlık kaygısı arasında anlamlı korelasyon belirlenmemiștir $(\mathrm{p}>0,05)$.

Bu sonuçlar doğrultusunda; Hemşirelerin hasta ambulasyonuna yönelik olarak çalıştıkları klinik alana ilişkin eğitimlerinin desteklenmesi, iş yaşamına ilişkin süreçlerin hemşirelerin sağlık kaygısı üzerindeki etkisinin fark edilerek buna yönelik düzenlemelerin (personel sayısı, ekip çalışması vb.) yönetici iş birliği ile gerçekleştirilmesi, ve olası vaka sayılarındaki değişiklikler için hemşirelerin hem çalışma koşullarının iyileştirilmesi, hem de eğitim imkanlarının arttırılarak güçlendirilmesi önerilmektedir.

\section{Çıkar Çatışması}

Çıkar çatışması yoktur.

\section{Yazar Katkısı}

Afitap ÖZDELIKKARA; Fikir/Kavram, Tasarım, Analiz ve Yorum, Literatür taraması, Makale yazımı, Eleştirel inceleme.

Emine YAMAN; Fikir/Kavram, Tasarım, Veri toplama, Literatür taraması, Eleştirel İnceleme.

\section{KAYNAKLAR}

Alsubhi, H, Meskell, P, Shea, DO, Doody, O. (2020). Missed nursing care and nurses' intention to leave: An integrative review. J Nurs Manag, 28: 1830- 1840. https://doi.org/10.1111/jonm.13069.

Arpacıoğlu, M.S., Baltacı, Z. \& Ünübol, B. (2021). COVID-19 pandemisinde sağlık çalışanlarında tükenmişlik, Covid korkusu, depresyon, mesleki doyum düzeyleri ve ilişkili faktörler Cukurova Med J, 46(1):88-100 https://doi. org10.17826/cumj.785609.

Chen, Q., Liang, M., Li, Y., Guo, J., Fei, D. \& Wang, L, et al. (2020). Mental health care for medical staff in China during the COVID-19 outbreak. Lancet Psychiatry, 7, 15-16. https://doi.org/10.1016/S2215-0366(20)30078-X

Çiçek, B. \& Almalı, V. (2020). COVID-19 Pandemisi Sürecinde Kaygı Öz-yeterlilik ve Psikolojik lyi Oluş Arasındaki Iliş̧ki: Özel Sektör ve Kamu Çalışanları Karşılaştırması. Electronic Turkish Studies, 15(4):241-260.

Cho, S.H., Lee, J.Y., You, S.J., Song, K.J.\& Hong KJ. (2020). Nurse staffing, nurses prioritization, missed care, quality of nursing care, and nurse outcomes. Int J Nurs Pract. 26(1):12803. https://doi.org/10.1111/ijn.12803.

CSTS:Center for the Study of Traumatic Stress (2020). Sustaining the Well-Being of Healthcare Personnel during Coronavirus and other Infectious Disease Outbreaks. 2020. https://www.cstsonline.org/assets/media/ documents/CSTS_FS_Sustaining_Well_Being_Healthcare_Personn el_during.pdf.pdf. 
Duffy, J.R., Culp, S. \& Padrutt, T. (2018). Description and Factors Associated With Missed Nursing Care in an Acute Care Community Hospital. Journal of Nursing Administration, 48(7/8), 361-367. https://doi.org/10.1097/ NNA.0000000000000630.

Eskici, G.T. (2020). Hemşirelikte ekip çalışması ölçeğinin türkçeye uyarlanarak karşılanmayan hemşirelik bakımına etkisinin incelenmesi. (Yayınlanmamış Doktora Tezi). İstanbul Üniversitesi, İstanbul.

Griffiths, P., Dall'Ora C., Simon, M., Ball, J., Lindqvist, R. \& Rafferty A M. et al. (2014). Nurses' shift length and overtime working in 12 European countries: The association with perceived quality of care and patient safety. Medical саге, 52(11), 975-981. https://doi.org/10.1097/MLR.0000000000000233.

Henderson, J, Willis, E, Blackman, I, Verrall, C. \& McNeill, L. (2021). Comparing infection control and ward nurses' views of the omission of infection control activities using the Missed Nursing Care Infection Prevention and Control (MNCIPC) Survey. J Nurs Manag, 1- 11. https://doi.org/10.1111/jonm.13261.

Hessels, A.J., Flynn, L., Cimiotti, J.P., Cadmus, E. \& Gershon, R.R. (2015). The Impact of the Nursing Practice Environment on Missed Nursing Care. Clin Nurs Stud, 3(4):60-65. https://doi.org/10.5430/cns.v3n4p60

ICN(2020). Confirms 1,500 nurses have died from COVID-19 in 44 countries and estimates that healthcare worker COVID-19 fatalities worldwide could be more than 20,000. https://www.icn.ch/news/icn-confirms-1500nurses-have-died-covid-19-44-countries-and-estimates-healthcare-worker-covid.

Jiang, L., Broome, M. E., \& Ning, C. (2020). The performance and professionalism of nurses in the fight against the new outbreak of COVID-19 epidemic is laudable. International journal of nursing studies, 107, 103578. https:// doi.org/10.1016/j.ijnurstu.2020.103578.

Kalanlar, B. \& Kubilay, G. (2015). Afetlerde toplum sağlığının korunmasında önemli bir kavram: Afet hemşireliği. FN Hem Derg, 23(1):57-65

Kalischi, B.J, Landstrom, G.L. \& Hinshaw, A.S. (2009). Missed nursing care: a concept analysis. J Adv Nurs, 65(7):150917. https://doi.org/10.1111/j.1365-2648.2009.05027.x.

Kalisch, B.J. \& Xie B. (2014). Errors of Omission: Missed Nursing Care. West J Nurs Res. 36(7):875-90. https://doi. org/10.1177/0193945914531859.

Kalisch, B.J., Terzioglu, F. \& Duygulu, S. (2012). The MISSCARE Survey-Turkish: psychometric properties and findings. Nurs Econ, 30(1):29-37.

Kalischi, B.J, Tschannen, D. Lee, H. \& Friese CR. (2011). Hospital variation in missed nursing care. Am J Med Qual. 26(4):291-9. https://doi.org/10.1177/1062860610395929.

Lai, J., Ma, S., Wang, Y., Cai, Z., Hu, J. \& We N. et al.(2020). Factors Associated With Mental Health Outcomes Among Health Care Workers Exposed to Coronavirus Disease 2019. JAMA Netw Open, 3(3):e203976. https:// doi.org10.1001/jamanetworkopen.2020.3976.

Ilaslan, N. \& Yıldırım, ş.N. (2019). Bir üniversite hastanesinde hemşirelerin karşılanmayan hemşirelik bakım gereksinimi miktarı ve nedenlerine yönelik değerlendirmeleri. Cukurova Med J 2019;44(4):1226-1236. https:// doi.org/10.17826/cumj.509488.

OECD: The Organisation for Economic Co-operation and Development (2021). Nurses (indicator). https://doi. org/10.1787/283e64de-en.

Palese, A., Ambrosi, E., Prosperi, L., Guarnier, A., Barelli, P. \& Zambiasi, P.et al. (2015). Missed nursing care and 
predicting factors in the Italian medical care setting. Intern Emerg Med. 10(6):693-702. https://doi.org/10.1007/ s11739-015-1232-6.

Saqer, T.J. \& AbuAlRub, R.F. (2018). Missed nursing care and its relationship with confidence in delegation among hospital nurses. J Clin Nurs, 27(13-14):2887-2895. https://doi.org/10.1111/jocn.14380.

Sampaio, F., Sequeira, C. \& Teixeira, L. (2020). Nurses' Mental Health During the Covid-19 Outbreak: A CrossSectional Study. J Occup Environ Med. 62(10):783-787. https://doi.org/10.1097/JOM.0000000000001987.

Şimşekoğlu, N. \& Mayda, A.S. (2016). Bir üniversite hastanesinde görevli hemşirelerin sağlkkı yaşam biçimi davranışları ve sağlık kaygısı düzeyleri. Düzce Üniv Sağ Bil Enst Derg. 6(1):19-29.

T.C. Resmi Gazete 19.04.2011. Hemşirelik yönetmeliğinde değişiklik yapılmasına dair yönetmelik. Sayl: 27910 https://www.resmigazete.gov.tr/eskiler/2011/04/20110419-5.htm.

von Vogelsang, A.-C., Göransson, K. E., Falk, A.-C., \& Nymark, C. (2021). Missed nursing care during the COVID-19 pandemic: A comparative observational study. Journal of Nursing Management, 00, 1- 10. https://doi. org/10.1111/jonm.13392

White, E.M., Aiken, L.H.\& McHugh, M.D. (2019). Registered Nurse Burnout, Job Dissatisfaction, and Missed Care in Nursing Homes. J Am Geriatr Soc, 67(10):2065-2071. https://doi.org/10.1111/jgs.16051.

WHO Announces COVID-19 Outbreak a Pandemic (2020). https://www.euro.who.int/en/health-topics/healthemergencies/coronavirus-covid-19/news/news/2020/3/who-announces-covid-19-outbreak-a-pandemic pandemic.

Zencir, G. \& Eşer I. (2015). Hemşirelikte yeni bir kavram: karşılanamayan hemşirelik bakımı. Ege Üniversitesi Hemşirelik Fakültesi Dergisi, 31(1): 83-94. 